\title{
Mutual Acceptance of Data (MAD)
}

\section{K.S. Rao*}

In this short bulleting, I wish to bring to your attention an extremely important DEPARTURE of the agency to consider non-animal data as default which can sometimes be as important or even more. This is very historic in the umbrella of Mutual Acceptance of Data (MAD) that OECD will consider accepting non-animal data in support of safety, as a default.

A. OECD aims to extend acceptance of non-animal test data

Defined approach' for skin sensitization tests would fall within MAD scheme

The OECD has launched a project to create a system for interpreting data, in an effort to extend use of non-animal testing through the Mutual Acceptance of Data (MAD) scheme.

MAD can rarely be applied to non-standalone alternative test data because of complex relationships between test methods and prediction models that associate data from multiple sources.

The OECD project - adopted at the recent meeting of the working group of the national coordinators of the test guidelines programme (WNT) - aims to overcome this issue by developing a "defined approach" to interpreting non-animal test data.

"A defined approach is a fixed, data interpretation procedure that applies to various sources of information," says WNT chair Tim Singer, who is director general of environmental and radiation health sciences at Health Canada.

This will be produced in the form of an OECD test guideline document.

Proposed by the European Commission Joint Research Centre (JRC), in collaboration with the US and Canada, he adds that the project represents "new ground" for the test guidelines programme.

"It's a decision-tree that has fairly rigorous, unambiguous, objective criteria." He notes that the approach should not be confused with the Integrated Approach to Testing and Assessment (IATA).

The first example, being created by the JRC, will focus on non-animal test methods for skin sensitization. This will show how the methods - such as in vitro, physico-chemical and QSAR - should be linked together to make predictions.

The approach is likely to be ready for review by the WNT in 2019 or 2020 . He adds that the project team "will be mindful of the financial costs of the relevant test methods, in order to avoid creating disincentives for the use of non-animal approaches".

\section{B. Defined Approaches}

Case studies for defined approaches to non-animal test methods for skin sensitization already exist. Last year, the OECD published 12 as part of a scoping initiative, conducted for its IATA program. They included some from industry, as well as scientific government bodies. The project will not be restricted to these 12 approaches. It will consider all relevant non-animal tests.

The OECD has published test guidelines documents for three non-animal skin sensitization test methods.

1. 442C for in chemico skin sensitization via the Direct Peptide Reactivity Assay (DPRA)

2. $442 \mathrm{D}$ for in vitro skin sensitization via the ARENrf2 luciferase (Keratinosens) method

3. $442 \mathrm{E}$ for in vitro skin sensitization via the Human Cell Line Activation Test (h-CLAT) and augmented in April with two other in vitro methods addressing the same key event, that is, activation of dendritic cells (IL8-Luc and U-Sens).

Further test methods are in the OECD's validation pipeline. These includes:

1. The Genomic Assay Rapid Detection test for skin (GARDskin), which was developed by Swedish CRO Senzagen.

2. The SENS-IS assay developed by French CRO Immunosearch. This involves toxico-genomic analysis of 3D reconstituted epidermis.

\section{Mutual Acceptance of Data (MAD)}

Within the MAD scheme, OECD member countries and others signed up to the scheme, accept each other's toxicity test data if it has been generated following OECD Test Guidelines and Good Laboratory Practice. This minimizes the total number of tests that must be conducted, benefiting industry and government. Usually, risk assessors can make a prediction about a specific hazard endpoint from a single animal test method. But they require multiple nonanimal test methods to achieve the same.

\section{EU - REACH}

Last year, European Chemical Agency (ECHA) amended the REACH annexes with respect to nonanimal test methods for skin sensitization. The agency also stated the methods were to be considered the "default" under REACH. Earlier this year, the European Union body for test method validation concluded that some of the 12 potential defined approaches, published by the OECD, were better than the standard animal test method.

\section{DISCLAIMER}

This newsletter is solely intended for educational purpose. Some of the contents of this newsletter may have been adopted without or with modification from other published resources.

\section{K.S. Rao*}

Development of Strategic Business, Advinus Therapeutics Ltd, Peenya Industrial Area, Bengaluru, Karnataka, INDIA.

\section{Correspondence}

Dr. K.S. Rao, M.V.Sc., Ph.D., DABT.

Senior Director-Development of Strategic Business, Advinus Therapeutics Ltd, 21 and 22, Phase II, Peenya Industrial Area, Bengaluru-560 058, Karnataka, INDIA.

Ph.no: +91 7337830074

Email: toxrao@gmail.com

History

- Submission Date: 25-06-2018;

- Review completed: 16-07-2018;

- Accepted Date: 29-07-2018.

DOI : 10.5530/bems.5.1.4

Article Available online http://www.bemsreports.org

Copyright

(C) 2019 Phcog.Net. This is an openaccess article distributed under the terms of the Creative Commons Attribution 4.0 International license. 